Ethiopian Journal of Environmental Studies \& Management 9(6): 738 - 747, 2016.

ISSN:1998-0507

Submitted: July 02, 2016

doi: http://dx.doi.org/10.4314/ejesm.v9i6.6

\title{
TRENDS IN MONTHLY RAINFALL AND TEMPERATURE IN RACHUONYO NORTH SUB-COUNTY, KENYA
}

\author{
OPERE, E., ${ }^{*}$ *JUMA, S.G. ${ }^{2}$ AND SITIENEI, B. ${ }^{2}$ \\ ${ }^{1}$ Department of Meteorology, University of Nairobi, Kenya \\ ${ }^{2}$ Department of Mathematics, Kibabii University, Kenya
}

\begin{abstract}
We analyse Climate Research Unit (CRU) Precipitation (1961-2014) and Temperature (1985-2014) data trends over Rachuonyo North Sub County at 50×50 km resolution. Time series and correlation analysis of the data was carried out. Temporal characteristics of temperature and Rainfall were determined. One sample t-tailed test of hypothesis was carried out. An increasing trend in temperature is observed over the years while a decreasing trend in precipitation is observed by the year 2014. The trends exhibited a cyclic and Seasonal pattern with Increasing Variability. Descriptive statistics revealed Rainfall and Temperature Means of $119.8 \mathrm{~mm}$ and $19.6{ }^{\circ} \mathrm{C}$ respectively. The results of one tailed $t$-test revealed that the change in Rainfall and temperature patterns over the area of study were not statistically significant.
\end{abstract}

Key Words: Climate Change, Temperature, Rainfall Trend, Rachuonyo, Kenya

\section{Introduction}

Anthropogenic increases in the wellmixed greenhouse gases (WMGHGs) have substantially enhanced the greenhouse effect, and the resulting forcing continues to increase, (IPCC 2013). According to the report of Intergovernmental panel on climate Change (IPCC, 2013), it is certain (with 95\% confidence) that the global mean surface temperature of the earth has increased since the beginning of the instrumental record. This warming has been about $0.85^{\circ} \mathrm{C}$ from 1880 to 2012 with an increase of about $0.72{ }^{\circ} \mathrm{C}$ from 1951 to 2012. Each of the last three decades has successively been the warmest on record. They also have very likely (over $90 \%$ probability) been the warmest in the last 800 years and likely (over $66 \%$ probability) the warmest in the last 1400 years even if the rate of warming over the last 15 years is smaller than the rate since the 1950s (IPCC 2013).

Schreck et al. (2004) carried out a study whose primary objective was to investigate the recent variability of the eastern African climate. The region of interest comprised of countries of Burundi, Djibouti, Eritrea, Ethiopia, Kenya, Rwanda, Somalia, Sudan, Uganda, and Tanzania. The analysis was based primarily on the construction of empirical orthogonal functions (EOFs) of gauge rainfall data and on CPC Merged

*Corresponding Author: Shema, S.G.

Email: shemmax@students.uonbi.ac.ke 
Analysis of Precipitation (CMAP) data, derived from a combination of rain-gauge observations and satellite estimates. The investigation was based on the period 1961-2001 for the 'short rains' season of eastern Africa of October through to December. The EOF analysis was supplemented by projection of National Centers for Environmental Prediction wind data onto the rainfall Eigen modes to understand the rainfall-circulation relationships. Furthermore, correlation and composite analyses were performed with the Climatic Research Unit globally averaged surface-temperature time series to explore the potential relationship between the climate of eastern Africa and global warming.

Results of the study revealed that most dominant mode of variability (EOF1) based on CMAP data over eastern Africa corresponded to El Niñosouthern oscillation (ENSO) climate variability. It was associated with abovenormal rainfall amounts during the short rains throughout the entire region, except for Sudan. The corresponding anomalous low-level circulation was dominated by easterly inflow from the Indian Ocean, and to a lesser extent the Congo tropical rain forest, into the positive rainfall anomaly region that extends across most of eastern Africa. The easterly inflow into eastern Africa was revealed to be part of diffluent outflow from the maritime continent during the warm ENSO events. The second eastern African EOF (trend mode) was associated with decadal variability. In distinct contrast from the ENSO mode pattern, the trend mode was seen to be characterized by positive rainfall anomalies over the northern sector of eastern Africa and opposite conditions over the southern sector. This rainfall trend mode eluded detection in previous studies that did not include recent decades of data, because the signal was still relatively weak. The wind projection onto this mode indicated that the primary flow that feeds the positive anomaly region over the northern part of eastern Africa emanates primarily from the rainfall-deficient southern region of eastern Africa and Sudan.

Report by Funk et al. (2010) drew from a multi-year effort by the United States Agency for International Development's Famine Early Warning System Network (FEWS NET) to monitor and map rainfall and temperature trends over the last 50 years (1960-2009) in Kenya. Observations from seventy rainfall gauges and seventeen air temperature stations were analyzed for the long rains period, corresponding to March through June (MAMJ). The data were quality controlled, converted into 1960-2009 trend estimates, and interpolated using a rigorous geostatistical technique (kriging). Kriging produces standard error estimates, and these can be used to assess the relative spatial accuracy of the identified trends. Dividing the trends by the associated errors allowed the researchers to identify the relative certainty of estimates (Verdin and others, 2005; Brown and Funk, 2008.) This study revealed a significant increase in temperature and reduction in rainfall. Studies by Muthama et al. (2015) revealed that Kenya will experience warming by the year 20100 .

\section{Objectives of the study}

The main objective was to analyze the trend of rainfall and temperature data over the area of study. The specific objective of this study was to determine 
the past trends in rainfall and temperature over the study region

\section{Area of study}

Rachuonyo North Sub County's climate is a tropical humid and strongly dominated by the influence of $\mathrm{L}$. Victoria. Humidity is high with potential evapo-transpiration rate between 2000 and $2200 \mathrm{~mm}$ per year. Annual temperature in the sub county range from 17 to $34^{\circ} \mathrm{C}$. February is the hottest month while temperature are lowest in April and November. Yearly average precipitation is between 700 and $1800 \mathrm{~mm}$ with an annual average of around $949 \mathrm{~mm}$.

Figure 1 below shows area of study. The sub county is located in Homa Bay County at $0.6221^{\circ} \mathrm{S}, 34.3310^{\circ} \mathrm{E}$ in
Kenya. The Sub-County is part of Homabay County that is endowed with major tourism attraction sites including Ruma National park, Kanjera archeological site, Simbi Nyaima (volcanic Crater Lake), Mfangano and Rusinga Islands. Homabay County is divided into seven agro-ecological zones namely upper Midland (UM 1), coffee tea zone, Upper Midland (UM 3); Marginal coffee zone, Upper midland (UM 4); sunflower-Maize zone, Lower Midland (LM 2); Marginal sugar zone, Lower Midland (LM 3); Cotton zone, Lower Midland (LM 4), Marginal cotton zone, Lower Midland (LM 5); Livestock-millet zone. Rachuonyo North Sub-County is trespassed by the last two agro-ecological zones.

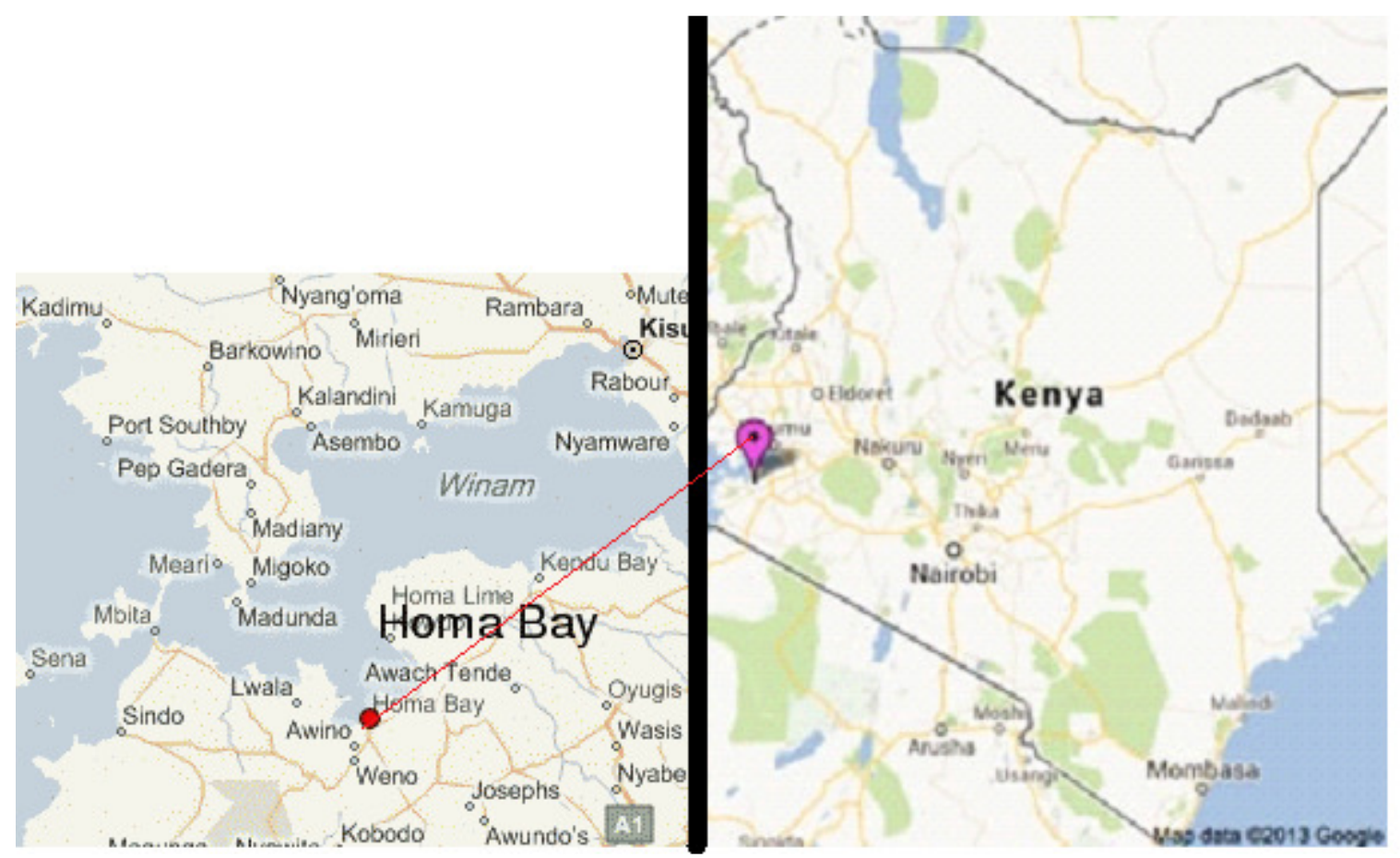

(Source: Map@ 2013 google)

Figure 1: Map of the study area 


\section{Data}

Gridded Climate Research Unit (CRU) Rainfall Data spanning 1961-2014 and temperature data spanning 19852014 was obtained from http://www.cru.uea.ac.uk/data managed by the University of East Angilia with a data resolution of $0.5^{\circ} \times 5^{\circ}$.

\section{Methodology}

Temporal analysis of Rainfall and Temperature

Time series analysis of Climate data was done over the area of study. Temporal Characteristics of rainfall and temperature were determined. Time series analysis was employed because there was need to whether the data points of the climate data had any internal structure like trend or seasonal variation.
The following formula was used to determine time series for variable Y:

$\mathrm{Yt}=\mathrm{b} 0+\mathrm{b} 1(\mathrm{t})+\mathrm{t} \ldots \ldots \ldots \ldots \ldots \ldots(\mathrm{i})$

Where :

Yt is the value of the time series (Dependent Variable at time $(\mathrm{t})$

b0 is y intercept

b1 is trend coefficient

$t$ is error term

$\mathrm{t}$ is the independent variable (time)

\section{Results and Discussion}

The temporal variation of temperature over the area of study is shown in Figure 2. A cyclic pattern and increasing trend can be seen attributable to increasing Climate variability and/or Change over the area of study.

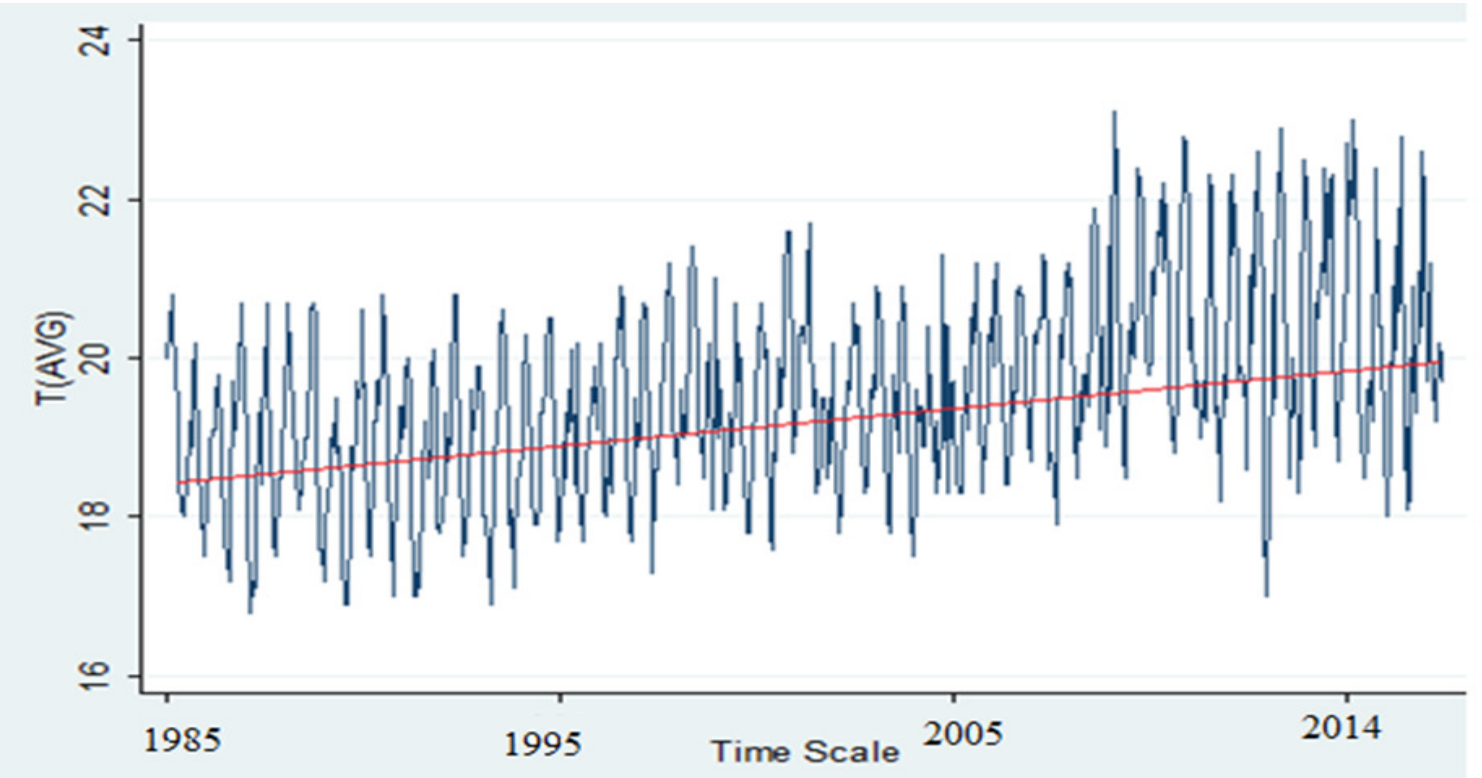

Figure 2: Variation of average temperature spanning 1985-2014 over the area of study

Results from figure 3 below also show the seasonal variation of temperature in DJF season across the years of investigation. The results show a seasonal pattern in temperature with a clearly increasing variability, a feature that can be attributed to increasing Climate Variability and/or Climate Change. 


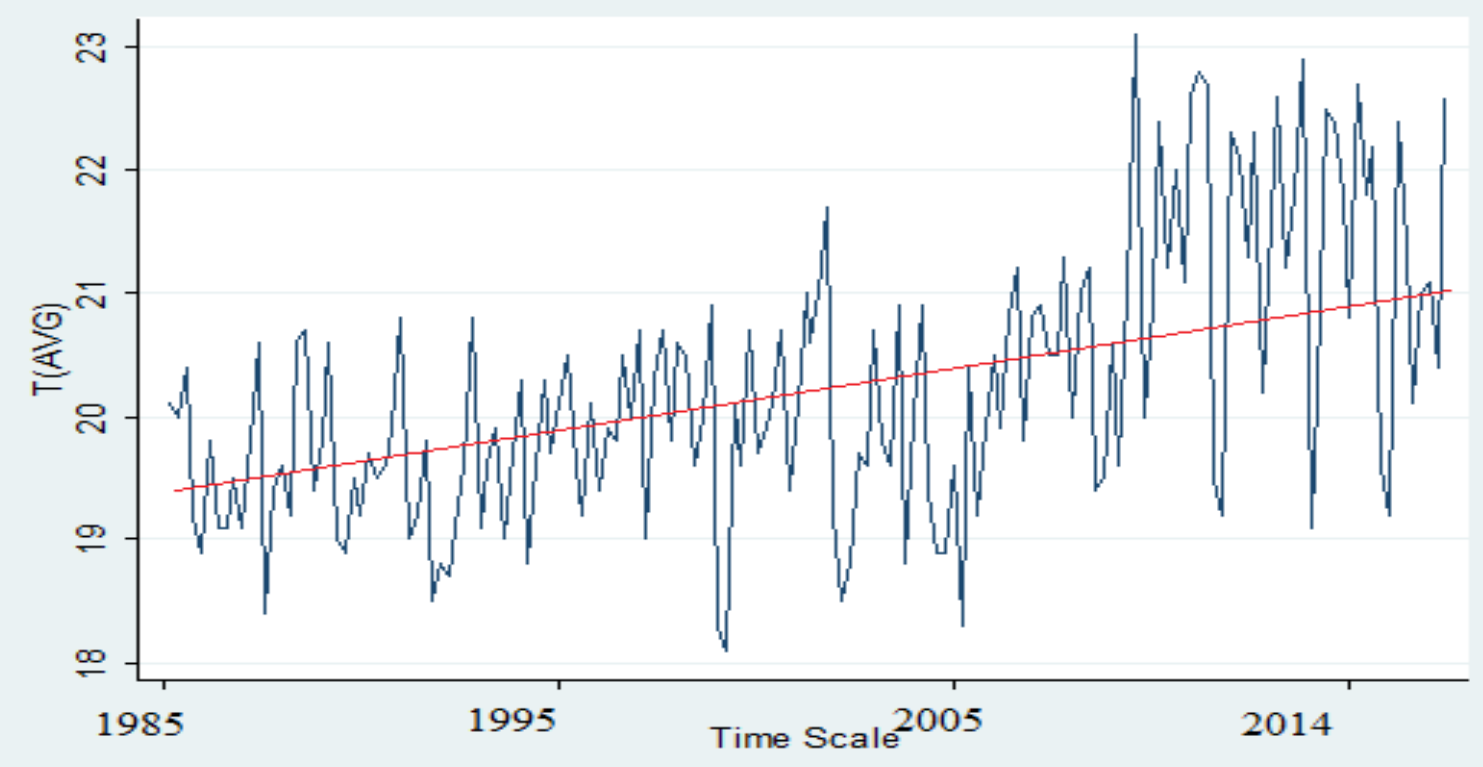

Figure 3: Variation of mean temperature in the DJF season spanning 1985-2014

Results from figure 4 below also show the seasonal variation of temperature in MAM season across the years of investigation. The results show a seasonal pattern in temperature with a clearly increasing variability, a feature that can be attributed to increasing Climate Variability and/or Climate Change.

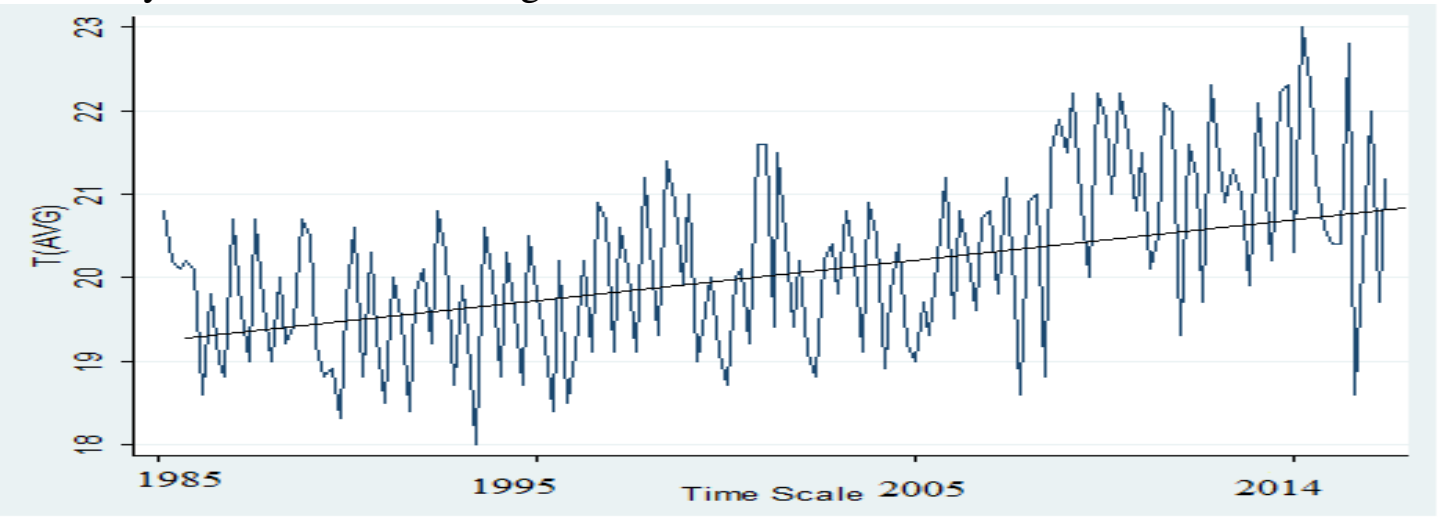

Figure 4: Variation of mean temperature in the MAM season spanning 1985-2014

Results from figure 5 below also show the seasonal variation of temperature in JJA season across the years of investigation. The results show a seasonal pattern in temperature with a clearly increasing variability, a feature that can be attributed to increasing Climate Variability and/or Climate Change. 


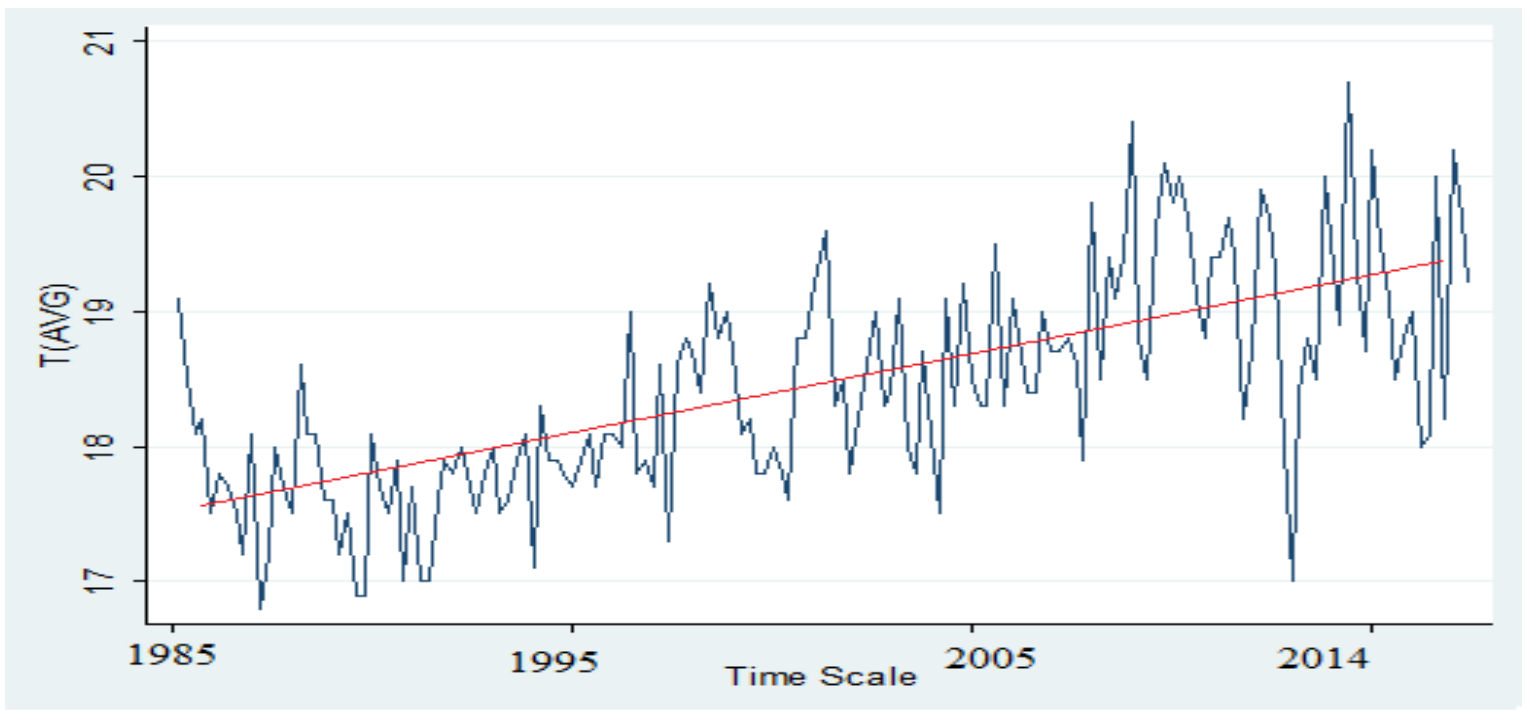

Figure 5: Variation of mean temperature in the JJA season spanning 1985-2014.

Results from figure 6 below also show the seasonal variation of temperature in SON season across the years of investigation. The results show a seasonal pattern in temperature with a clearly increasing variability, a feature that can be attributed to increasing Climate Variability and/or Climate Change.

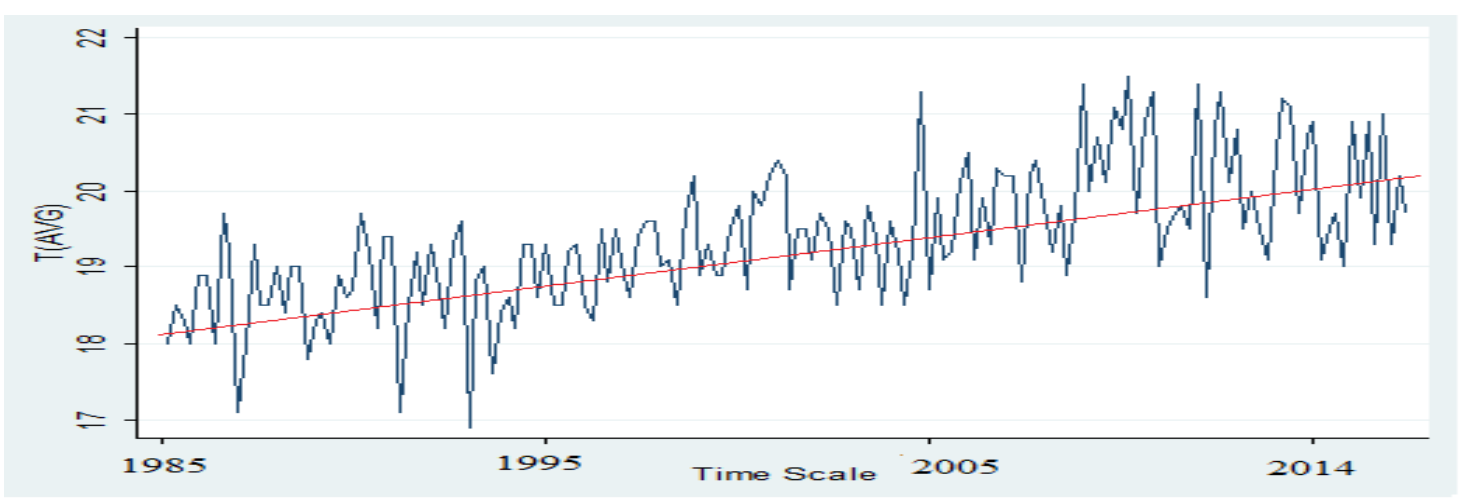

Figure 6: Variation of mean temperature in the SON season spanning 1985-2014.

Results of time series analysis of rainfall over the area of study are shown in Figure 7. A cyclic trend can be seen with an increasingly varying frequency in the peaks and reducing trend in rainfall amounts attributable to increasing Climate variability and/or Change over the area of study. Seasonal characteristics of rainfall over the area of study are depicted in figures 8 to 11 below. 


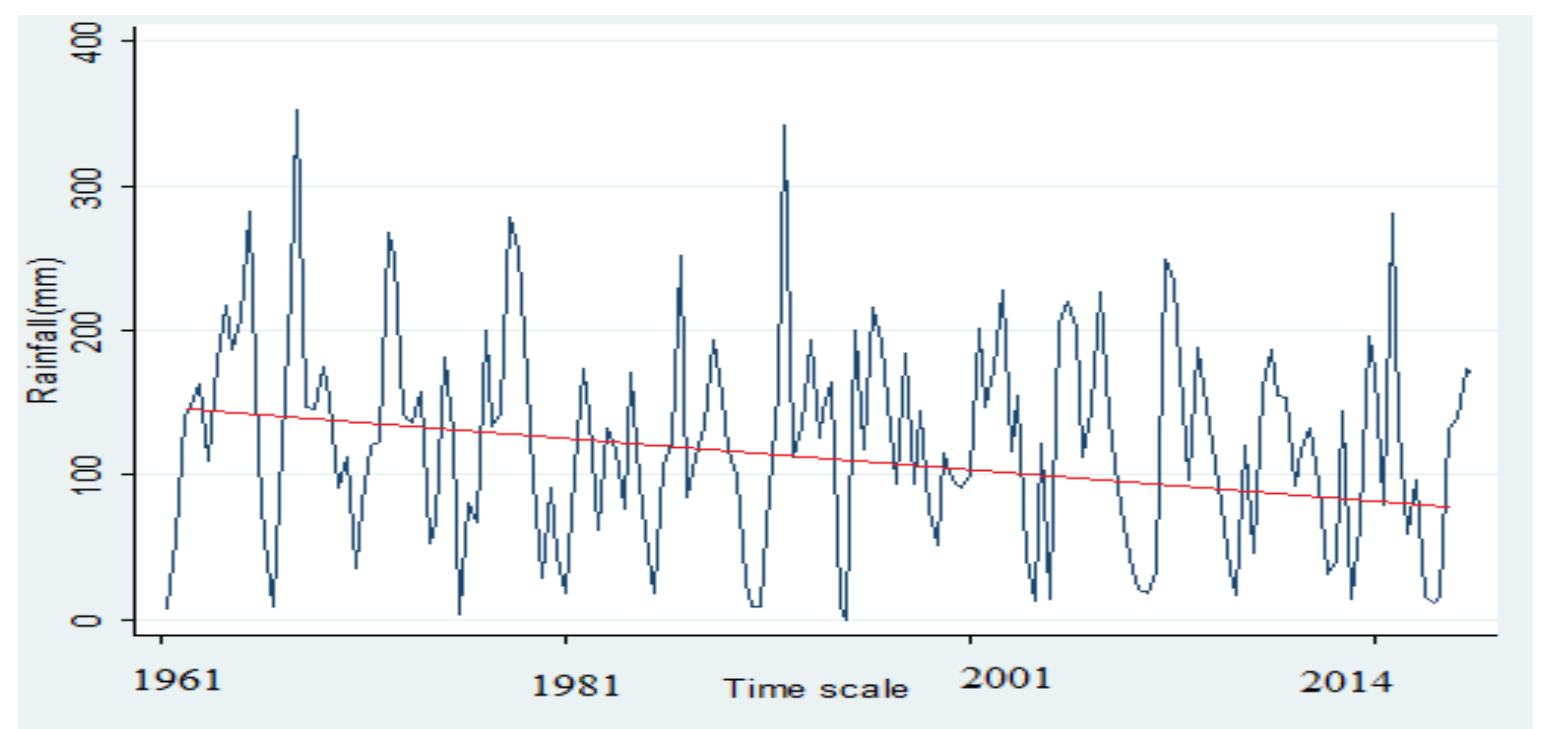

Figure7: Variation of rainfall amount over the area of study spanning 1961-2014.

Figure 8 below shows temporal characteristics of rainfall during MAM season over the area of study. A generally increasing variability of rainfall can be seen with a reducing trend towards the most recent years. This can be explained by possible climate change over the area of study.

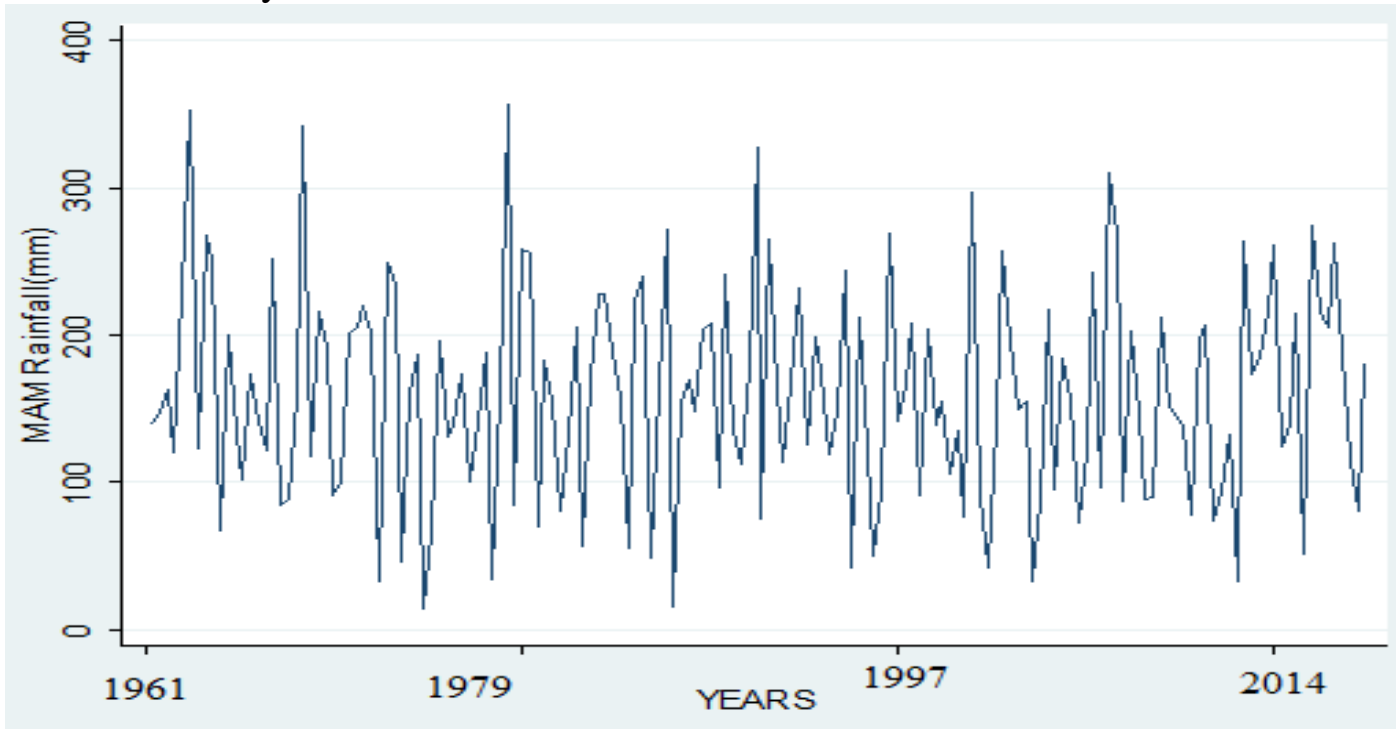

Figure 8: Variation of rainfall amount during the MAM season over the area of study spanning 1961-2014

Figure 9 below shows temporal characteristics of rainfall during JJA season over the area of study. A generally increasing variability of rainfall towards the most recent years. This can be explained by possible climate change over the area of study. 


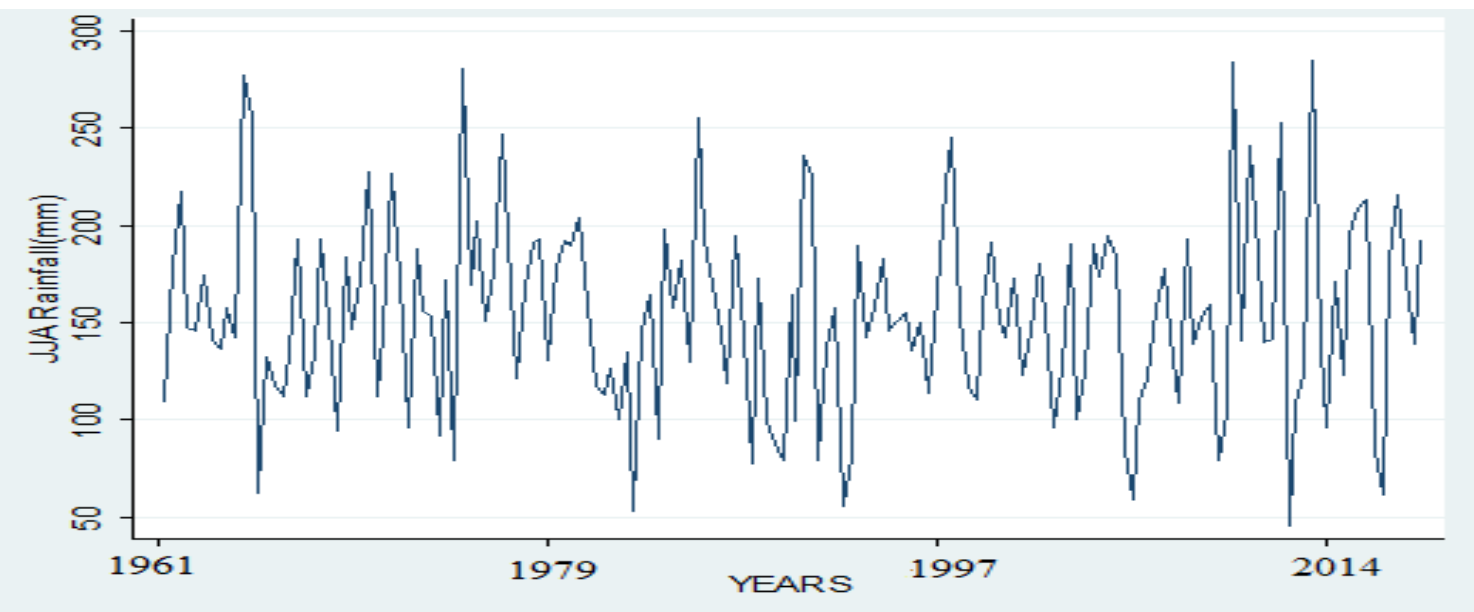

Figure 9: Variation of rainfall amount during the JJA season over the area of study spanning 1961-2014

Figure 10 below shows temporal characteristics of rainfall during DJF season over the area of study. A generally increasing variability of rainfall can be seen with reducing intensity of the peaks towards the most recent years. This can be explained by possible climate change over the area of study.

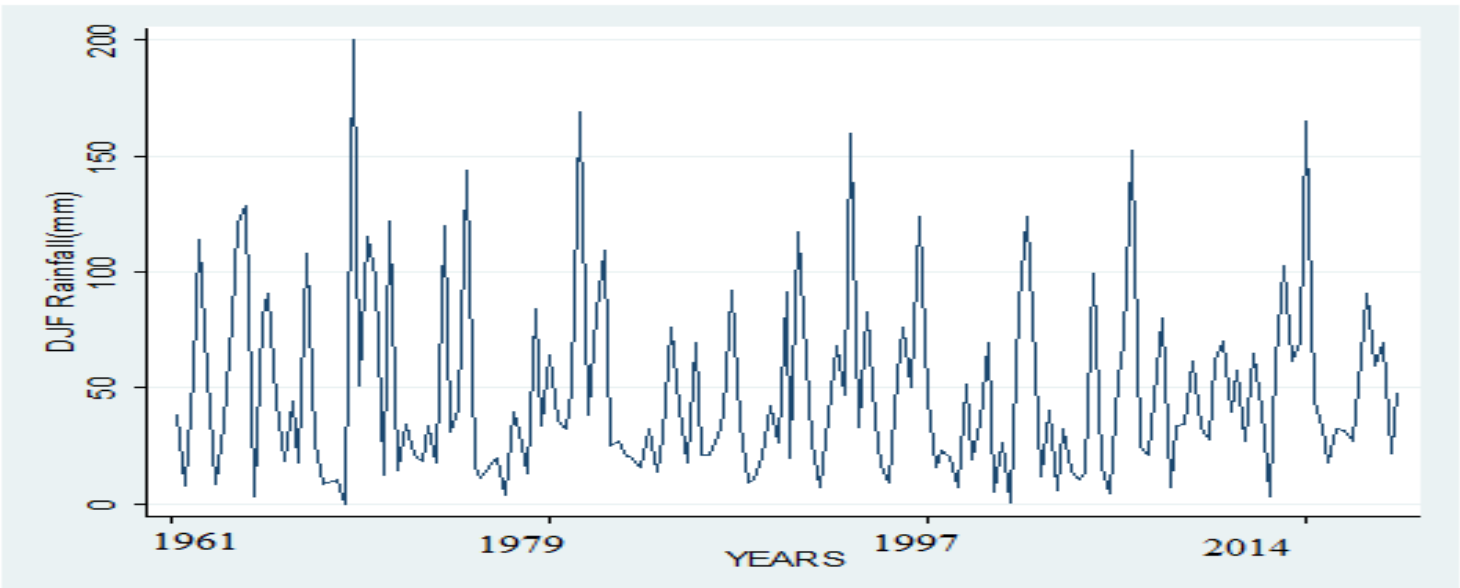

Figure 10: Variation of rainfall amount during the DJF season over the area of study spanning 1961-2014

Figure 11 below shows temporal characteristics of rainfall during SON season over the area of study. A generally increasing variability of rainfall can be seen with increasing intensity towards the most recent years. This can be explained by possible climate change over the area of study. 


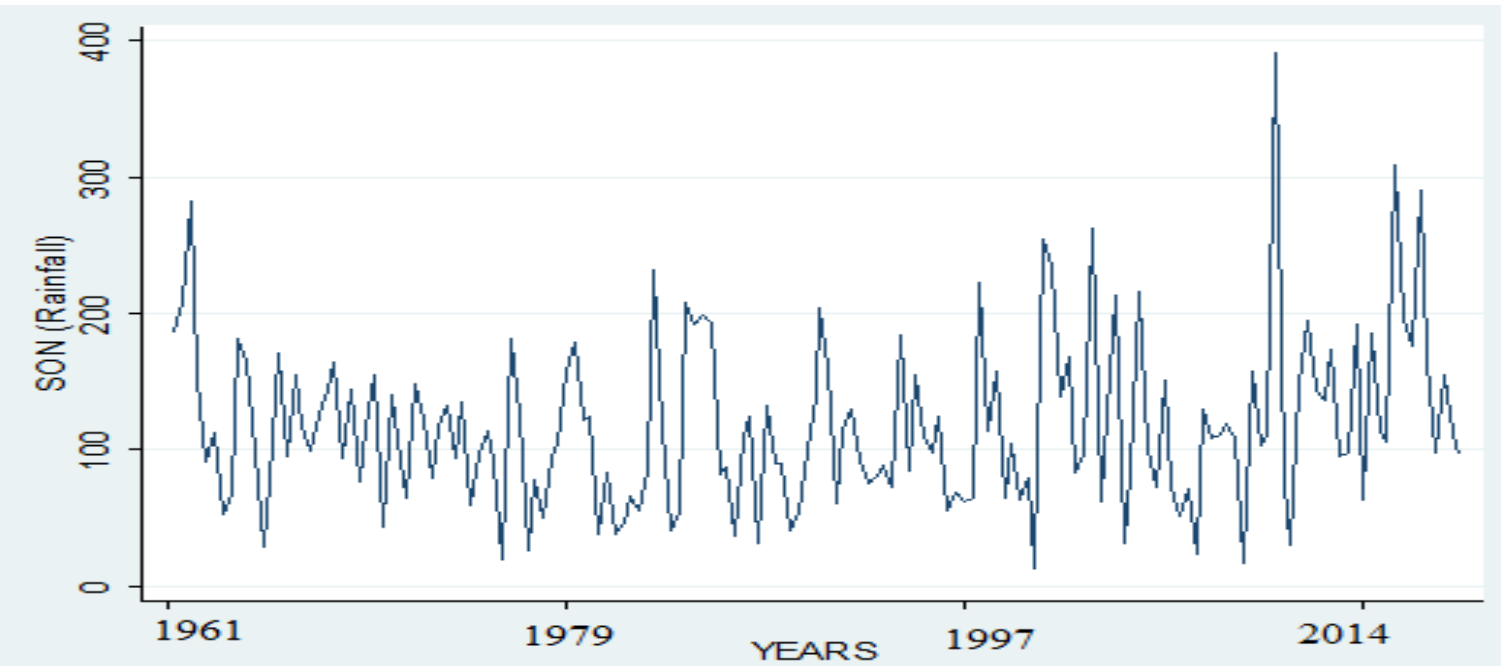

Figure 11: Variation of rainfall amount during the SON season over the area of study spanning 1961-2014

The increasing variability observed across all seasons can be attributed to temperature and rainfall anomalies associated with the decline in temperature zone westerlies and increased frequency of blocking in high latitutes. El Niño/La Niña phases can also be associated with wet/dry periods over the region while for the JJA seasons, Atlantic SSTs could have negative loadings centred on the tropical western Atlantic Ocean associated with the wet/dry regimes over the region.Positive loading of atlantic SSTs may be identified with DJF, MAM and SOND seasons. Easterly inflow into eastern Africa can be part of diffluent outflow from the maritime continent during the warm ENSO events. The second eastern African EOF (trend mode) can be associated with decadal variability. In distinct contrast from the ENSO mode pattern, the trends are seen to be characterized by positive rainfall peaks over area. This rainfall trend shows that the signal is becoming stronger, in general; over the most recent years.
However, the attributions in this paper should not be judged as comprehensive.

\section{Recommendations}

This research recommends uncertainty analysis and intercomparison of both parametric and non-parametric tests of significance. The former assumes that data exhibits a certain distribution while the later does not assume that data exhibits a certain distribution, While a one sample t-test was carried out in this research, the research recommends other parametric methods like two sample ttest, One-Way-ANOVA and nonparametric tests including Mann-Whitney test, Friedman test among others.

\section{References}

Funk, C. and Verdin, J. P. (2010). Realtime decision support systems: the famine early warning system network. In Satellite rainfall applications for surface hydrology (pp. 295-320). Springer Netherlands. 
Funk, C., Eilerts, G., Davenport, F. and Michaelsen, J. (2010). A climate trend analysis of Kenya-August 2010. US Geological Survey Fact Sheet, 3074.

Schreck, C.J. and Semazzi, F.H. (2004). Variability of the recent climate of eastern Africa. International Journal of Climatology, 24(6): 681701.

Stocker, T.F., Qin, D., Plattner, G.K., Tignor, M., Allen, S. K., Boschung, J. and Midgley, B.M. (2013). IPCC,
2013: climate change 2013: the physical science basis. Contribution of working group I to the fifth assessment report of the intergovernmental panel on climate Verdin, J., Funk, C., Senay, G. and Choularton, R. (2005). Climate science and famine early warning. Philosophical Transactions of the Royal Society of London B: Biological Sciences, 360(1463), 2155-2168. 